\title{
Disparities in genetic services utilization in a random sample of young breast cancer survivors
}

\author{
Christos Nikolaidis, $\mathrm{PhD}^{1}$, Debra Duquette, MS, CGC 2,3 , Kari E. Mendelsohn-Victor, $\mathrm{MPH}^{4}$, \\ Beth Anderson, $\mathrm{MPH}^{3}$, Glenn Copeland, $\mathrm{MBA}^{3}$, Kara J. Milliron, MSc, $\mathrm{CGC}^{5}$, \\ Sofia D. Merajver, MD, PhD ${ }^{6,7}$, Nancy K. Janz, PhD ${ }^{6}$, Laurel L. Northouse, PhD, $\mathrm{RN}^{4}$, \\ Sonia A. Duffy, PhD, $\mathrm{RN}^{8}$ and Maria C. Katapodi, PhD, $\mathrm{RN}^{1,4}$
}

Purpose: Increasing use of genetic services (counseling/testing) among young breast cancer survivors (YBCS) can help decrease breast cancer incidence and mortality. The study examined use of genetic services between Black and White/Other YBCS, attitudes and knowledge of breast cancer risk factors, and reasons for disparities in using genetic services.

Methods: We used baseline data from a randomized control trial including a population-based, stratified random sample of 3000 potentially eligible YBCS, with oversampling of Black YBCS.

Results: Among 883 YBCS (353 Black, 530 White/Other) were significant disparities between the two racial groups. More White/ Other YBCS had received genetic counseling and had genetic testing than Blacks. Although White/Other YBCS resided farther away from board-certified genetic counseling centers, they had fewer barriers to access these services. Black race, high out-ofpocket costs, older age, and more years since diagnosis were negatively associated with use of genetic services. Black YBCS had lower knowledge of breast cancer risk factors. Higher education and genetic counseling were associated with higher genetic knowledge.

Conclusion: Racial inequalities of cost-related access to care and education create disparities in genetic services utilization. Systembased interventions that reduce socioeconomic disparities and empower YBCS with genetic knowledge, as well as physician referrals, can increase access to genetic services.

Genetics in Medicine (2019) 21:1363-1370; https://doi.org/10.1038/s41436018-0349-1

Keywords: equity in using cancer genetic services; geocoding; distance as a barrier to access genetic services; young breast cancer survivors; cancer registry

\section{INTRODUCTION}

Breast cancer is the most frequently diagnosed cancer and the second leading cause of cancer mortality among US women, with an estimated 252,710 new cases and 40,610 deaths in 2017 (ref. ${ }^{1}$ ). Notable disparities in breast cancer mortality have been documented among different racial groups, with mortality rates being $42 \%$ higher among Black women compared with Whites, regardless of similar incidence. ${ }^{2}$ This has been attributed to a combination of factors that include differences in stage at diagnosis, existence of comorbidities and tumor characteristics, as well as access and adherence to high-quality cancer treatment and prevention. ${ }^{3-5}$ Racial disparities in mortality have been documented for young breast cancer survivors (YBCS), a clinical group that includes women with a cancer diagnosis at a young age (age criteria for YBCS is variable from 40 to 50 years old and under). ${ }^{6}$ YBCS constitute a special population within the 3.6 million US breast cancer survivors. ${ }^{1}$ These women are at a higher risk of being carriers of germline pathogenic variants associated with hereditary cancer syndromes. ${ }^{7}$ Black YBCS experience a higher incidence of triple-negative breast cancer, a subtype with poorer survival, and are twice as likely to die from the disease compared with White YBCS, contributing to racial disparities in breast cancer mortality. ${ }^{3}$

Genetic testing for breast cancer susceptibility targets primarily germline pathogenic variants in the breast cancer 1 (BRCA1) and breast cancer 2 (BRCA2) genes, which confer a three- to sevenfold increase in the lifetime risk of breast and/ or ovarian cancer. ${ }^{8}$ Knowledge of genetic status is important, as it can inform clinical management options that include more intensive surveillance, chemoprevention and prophylactic risk-reducing surgery (i.e., double mastectomy, and/or

\footnotetext{
${ }^{1}$ Nursing Science, Faculty of Medicine, University of Basel, Basel, Switzerland; ${ }^{2}$ Feinberg School of Medicine, Northwestern University, Chicago, IL, USA; ${ }^{3}$ Michigan Department of Health and Human Services, Lansing, MI, USA; ${ }^{4}$ University of Michigan School of Nursing, Ann Arbor, MI, USA; ${ }^{5}$ Comprehensive Cancer Center, University of Michigan, Ann Arbor, MI, USA; ${ }^{6}$ University of Michigan School of Public Health, Ann Arbor, MI, USA; ${ }^{7}$ University of Michigan School of Medicine, Ann Arbor, MI, USA; ${ }^{8}$ Ohio State University College of Nursing, Columbus, OH, USA. Correspondence: Maria C. Katapodi (maria.katapodi@unibas.ch)
} 
salpingo-oophorectomy). ${ }^{9}$ However, cancer genetic services (counseling and testing) that provide credible information about these options are not equally utilized by all US women. Several studies have shown that Black women are accessing cancer genetic services disproportionately less than White women, mainly due to lack of awareness about the availability of genetic testing, ${ }^{10}$ lack of access to cancer genetics experts, ${ }^{11}$ geographic barriers, ${ }^{12}$ and other socioeconomic factors, including lack of insurance, lower education, and lower income. $^{13-15}$

Racial segregation and poverty have been traditionally identified as concordant barriers for accessing health care, leading to poor management of health risks among underserved communities. ${ }^{16-18}$ Yet, despite existing information, many more questions remain unanswered regarding the availability, accessibility, and acceptability of genetic services in these populations. The United States Preventive Services Task Force (USPSTF) recently identified this knowledge gap, and called for actions to improve the understanding of disparities in genetic service utilization among racial and ethnic minorities. ${ }^{19}$ The purpose of this study is to address this knowledge gap by examining reasons that explain use of cancer genetic services in YBCS, a population of cancer survivors where there is sparse information. The specific aims of the study were to (1) compare levels of genetic services utilization between Black and White/Other YBCS, (2) identify attitudes and knowledge of breast cancer risk factors, and (3) identify possible barriers that explain lack of genetic counseling and testing uptake, in a random sample of YBCS recruited from a statewide cancer registry. In a previous publication, we examined use of genetic services in Black YBCS. ${ }^{20}$ In this paper, we examine novel barriers for observed disparities in genetic services utilization between Black and White/Other YBCS, which have not been previously examined.

\section{MATERIALS AND METHODS}

\section{Design, sample, and procedures}

We used baseline data from a randomized trial conducted in the state of Michigan that tested the efficacy of two interventions designed to increase breast cancer surveillance and use of cancer genetic services among YBCS and their high-risk female relatives (ClinicalTrial.gov ID: NCT01612338). Methodological details of the study and the recruitment process have been described in detail elsewhere. $^{21,22}$ In brief, a racially stratified random sample of YBCS was selected from the Michigan Cancer Surveillance Program (MCSP). The MCSP is a population-based cancer registry that has been in operation since 1985, and has been certified by the National Association of Central Cancer Registries as to data quality, completeness, and timeliness since 1999. The initial sample of 3000 potentially eligible YBCS included 1500 Black and 1500 White/Other YBCS, with oversampling of Black YBCS to ensure their adequate representation in the study. ${ }^{22}$ Approximately $7 \%$ of YBCS of other racial backgrounds were grouped with White YBCS, because they could not form a separate stratum. YBCS were eligible to participate if they were (1) diagnosed with invasive breast cancer or ductal carcinoma in situ (DCIS) between 20 and 45 years of age, (2) Michigan residents at the time of diagnosis, (3) alive at the time of sampling, (4) 25 to 64 years old at the time of the study, (5) able to read English and provide informed consent, and (6) not pregnant, incarcerated, or institutionalized. Prior to contacting the YBCS, the MCSP mailed the reporting facility and the physician of record a letter asking if there was any reason that the YBCS should not be contacted for the study. An invitation letter explaining the study, a consent form, a self-administered baseline survey, and a stamped return envelope were mailed to YBCS. Eligible YBCS received up to three mailed invitations to participate in the study. Collection of baseline data from YBCS took place between September 2012 and January 2013. Institutional review boards of all organizations involved in identifying and recruiting YBCS approved the study protocol. ${ }^{21}$ Informed consent was obtained from all participants.

\section{Measures}

A survey collected self-reported demographic information (age, education, marital status, employment, income, insurance, access to health-care services) and clinical characteristics (number of cancer diagnoses, family history of cancer, surgical treatment, and use of genetic counseling and testing). An adapted version of the Theory of Planned Behavior guided data collection about knowledge (breast cancer risk factors and breast cancer genetics) and attitudes (perceived risk and fear of cancer recurrence). ${ }^{21}$ Items assessing knowledge of breast cancer risk factors and knowledge of breast cancer genetics were answered as "True," "False," or "Do not know" (with values assigned $+1,-1$, or 0 , respectively) to generate a knowledge score. ${ }^{23}$ Perceived breast cancer risk was assessed with a single item asking participants to rate their chances of getting cancer on a 10-point Likert scale with verbal anchors ("Definitely will not" to "Definitely will"). ${ }^{24}$ Fear of cancer recurrence was assessed with 4 items, on a 7-point Likert scale ranging from 1 ("Not at all") to 7 ("A great deal"). ${ }^{25}$ All measures were reliable with Cronbach a greater than 0.71 .

Distance from the nearest board-certified counseling center was considered a potential barrier for accessing genetic services and was calculated using ZIP code information. Minimum distance (in miles) from YBCS place of residence (at the time of the survey) to the nearest board-certified genetic counseling service was calculated using the great circle distance formula, ${ }^{26} \mathrm{D}=3963.0\left(\operatorname{arc} \cos \left[\sin \left(T_{1}\right)^{*} \sin \left(T_{2}\right)+\cos \right.\right.$ $\left.\left(T_{1}\right)^{\star} \cos \left(T_{2}\right)^{\star} \cos \left(G_{2}-G_{1}\right)\right]$, where $T_{\mathrm{i}}$ is the latitude and $G_{i}$ is the longitude of the specified locations in radians. Residential and genetic counseling center ZIP codes were geocoded as latitude/longitude coordinates using the R package "zipcode." Board-certified cancer genetic counseling centers, operating at the time of the survey, were identified from the National Society of Genetic Counselors (NSGC), the American College of Medical Genetics and Genomics (ACMG), and the National Cancer Institute (NCI) Cancer Genetics Services Directory. 
Table 1 Demographic characteristics of young breast cancer survivors (YBCS)

\begin{tabular}{|c|c|c|c|c|}
\hline Characteristic & YBCS & $\begin{array}{l}\text { White/ } \\
\text { Other }\end{array}$ & Black & $p$ value \\
\hline Cases & 859 & 519 & 340 & \\
\hline $\mathrm{Age}^{\mathrm{a}}$ & $\begin{array}{l}51 \pm \\
5.9\end{array}$ & $\begin{array}{l}51.2 \pm \\
6.0\end{array}$ & $\begin{array}{l}50.5 \pm \\
5.6\end{array}$ & 0.101 \\
\hline \multicolumn{5}{|l|}{ Marital status } \\
\hline Single & $\begin{array}{l}338 \\
(39.6)\end{array}$ & $\begin{array}{l}123 \\
(23.8)\end{array}$ & $\begin{array}{l}215 \\
(63.8)\end{array}$ & - \\
\hline Married/life partner & $\begin{array}{l}516 \\
(60.4)\end{array}$ & $\begin{array}{l}394 \\
(76.2)\end{array}$ & $\begin{array}{l}122 \\
(36.2)\end{array}$ & $<0.001$ \\
\hline \multicolumn{5}{|l|}{ Education } \\
\hline Not completed high school & $\begin{array}{l}34 \\
(4.0)\end{array}$ & $9(1.8)$ & $\begin{array}{l}25 \\
(7.4)\end{array}$ & - \\
\hline High school/technical school & $\begin{array}{l}165 \\
(19.4)\end{array}$ & $\begin{array}{l}88 \\
(17.2)\end{array}$ & $\begin{array}{l}77 \\
(22.9)\end{array}$ & - \\
\hline Some college/no degree & $\begin{array}{l}322 \\
(37.9)\end{array}$ & $\begin{array}{l}197 \\
(38.4)\end{array}$ & $\begin{array}{l}125 \\
(37.2)\end{array}$ & - \\
\hline Complete college & $\begin{array}{l}190 \\
(22.4)\end{array}$ & $\begin{array}{l}130 \\
(25.3)\end{array}$ & $\begin{array}{l}60 \\
(17.9)\end{array}$ & - \\
\hline Postgraduate degree & $\begin{array}{l}138 \\
(16.3)\end{array}$ & $\begin{array}{l}89 \\
(17.3)\end{array}$ & $\begin{array}{l}49 \\
(14.6)\end{array}$ & $<0.001$ \\
\hline \multicolumn{5}{|l|}{ Employment } \\
\hline Full time & $\begin{array}{l}424 \\
(51.3)\end{array}$ & $\begin{array}{l}274 \\
(55.1)\end{array}$ & $\begin{array}{l}150 \\
(45.5)\end{array}$ & - \\
\hline Part time & $\begin{array}{l}89 \\
(10.8)\end{array}$ & $\begin{array}{l}82 \\
(16.5)\end{array}$ & $7(2.1)$ & - \\
\hline Unemployed/other & $\begin{array}{l}314 \\
(38.0)\end{array}$ & $\begin{array}{l}141 \\
(28.4)\end{array}$ & $\begin{array}{l}173 \\
(52.4)\end{array}$ & $<0.001$ \\
\hline \multicolumn{5}{|l|}{ Income } \\
\hline$<\$ 20,000$ & $\begin{array}{l}130 \\
(17.9)\end{array}$ & $40(8.9)$ & $\begin{array}{l}90 \\
(31.5)\end{array}$ & - \\
\hline$\$ 20,000-\$ 39,999$ & $\begin{array}{l}123 \\
(16.9)\end{array}$ & $\begin{array}{l}55 \\
(12.2)\end{array}$ & $\begin{array}{l}68 \\
(23.8)\end{array}$ & - \\
\hline$\$ 40,000-\$ 59,999$ & $\begin{array}{l}136 \\
(18.7)\end{array}$ & $\begin{array}{l}79 \\
(17.5)\end{array}$ & $\begin{array}{l}57 \\
(19.9)\end{array}$ & - \\
\hline$\$ 60,000-\$ 79,999$ & $\begin{array}{l}101 \\
(13.9)\end{array}$ & $\begin{array}{l}78 \\
(17.3)\end{array}$ & $\begin{array}{l}23 \\
(8.0)\end{array}$ & - \\
\hline$\$ 80,000-\$ 99,999$ & $\begin{array}{l}66 \\
(9.1)\end{array}$ & $\begin{array}{l}46 \\
(10.2)\end{array}$ & $\begin{array}{l}20 \\
(7.0)\end{array}$ & - \\
\hline$\$ 100,000-\$ 119,999$ & $\begin{array}{l}67 \\
(9.2)\end{array}$ & $\begin{array}{l}59 \\
(13.1)\end{array}$ & $8(2.8)$ & - \\
\hline$\geq \$ 120,000$ & $\begin{array}{l}104 \\
(14.3)\end{array}$ & $\begin{array}{l}94 \\
(20.8)\end{array}$ & $\begin{array}{l}20 \\
(7.0)\end{array}$ & $<0.001$ \\
\hline \multicolumn{5}{|l|}{ Insurance } \\
\hline No insurance & $\begin{array}{l}56 \\
(6.5)\end{array}$ & $24(4.6)$ & $\begin{array}{l}32 \\
(9.4)\end{array}$ & 0.005 \\
\hline Medicaid & $\begin{array}{l}96 \\
(11.2)\end{array}$ & $21(4.0)$ & $\begin{array}{l}75 \\
(22.1)\end{array}$ & $<0.001$ \\
\hline Medicare & $\begin{array}{l}90 \\
(10.5)\end{array}$ & $34(6.6)$ & $\begin{array}{l}56 \\
(16.5)\end{array}$ & $<0.001$ \\
\hline Private/Other & $\begin{array}{l}617 \\
(71.8)\end{array}$ & $\begin{array}{l}440 \\
(84.8)\end{array}$ & $\begin{array}{l}177 \\
(52.1)\end{array}$ & $<0.001$ \\
\hline
\end{tabular}

Table 1 continued

\begin{tabular}{cllll}
\hline Characteristic & YBCS & $\begin{array}{l}\text { White/ } \\
\text { Other }\end{array}$ & Black & $p$ value \\
\hline Access to health-care services & & & \\
Routine source of care & 791 & 488 & 303 & $\mathbf{0 . 0 1 6}$ \\
& $(92.1)$ & $(94.0)$ & $(89.1)$ & \\
Lack of access due to high & 149 & 64 & 85 & $<\mathbf{0 . 0 0 1}$ \\
out-of-pocket cost & $(17.3)$ & $(12.3)$ & $(25.0)$ & \\
Lack of insurance & 56 & $24(4.6)$ & 32 & $\mathbf{0 . 0 0 5}$ \\
& $(6.5)$ & & $(9.4)$ & \\
Distance from genetic & 7.5 & 10.3 & 5.1 & $<\mathbf{0 . 0 0 1}^{\mathbf{c}}$ \\
counseling center $^{\mathrm{b}}$ & $(0-148)$ & $(0-148)$ & $(0-136)$ & \\
\hline
\end{tabular}

All values expressed as $n$ (\%) with valid percentages shown to account for missing values.

${ }^{\mathrm{a}}$ Mean \pm standard deviation

${ }^{\mathrm{b}}$ Median (range).

'Based on the Wilcoxon rank sum test.

\section{Statistical analyses}

We used descriptive statistics to inspect the data, identify missing values, and assess distributions. Frequencies and percentages described categorical variables. Means, ranges, and standard deviations were used for continuous variables. Bivariate analyses and inferential statistics, such as chi-square tests for differences in proportions, and $t$ tests for differences in means (and their nonparametric equivalents for nonnormally distributed data) examined relationships in demographic and clinical characteristics, use of genetic services, and knowledge and attitudes among YBCS. Linear regressions with simultaneous variable selection identified predictors of knowledge of breast cancer risk factors and genetics. Similarly, logistic regressions identified factors associated with the use of genetic counseling and testing. Two-tailed $p$ values were calculated with the level of significance set at $p<0.05$. A post hoc analysis in $G^{*}$ Power v.3.1 (ref. ${ }^{27}$ ) revealed that $>90 \%$ power $(a=0.05)$ could be achieved for all regressions. We used R software (version 3.4.1, R Core Team, 2017) for data analyses.

\section{RESULTS}

Of the 3000 randomly selected YBCS, 2960 (1486 Blacks and 1474 White/Others) were eligible to participate, and could be contacted. In total, 95 Blacks (6.4\%) and 179 White/Others (12.1\%) formally declined participation. Moreover, 832 Blacks (55.4\%) and 663 White/Others (44.2\%) who were eligible to participate and were invited to the study did not respond after three mailing attempts. In total, $883(33.2 \%)$ of contacted YBCS accepted participation; 353 were identified from the cancer registry as Black, and 530 as White/Other. The response rate was $38.6 \%$ for White/Other participants and $27.5 \%$ for Blacks. Most consented YBCS $(n=778,88.1 \%)$ resided in Michigan at the time of the survey and the remaining $(n=105,11.9 \%)$ resided in 23 other states. The most common reason for no response was lack of a current address $(n=252)$, especially for Black YBCS ( $n=175$ invalid addresses vs. $n=77$ among White/Others). Other known 
reasons for nonparticipation were YBCS was deceased $(n=$ $66)$, reporting physician advised against contact $(n=22)$, YBCS was incarcerated $(n=3)$. From the 883 YBCS who consented, 24 were ineligible because they were not diagnosed younger than 45 years old $(n=10)$, were pregnant $(n=9)$, or returned their survey too late $(n=5)$. The final sample consisted of 859 eligible YBCS, of whom 519 were White/ Other (60.4\%) and 340 (39.6\%) Black.

The mean age of YBCS at the time of the baseline survey was $51.0 \pm 5.9$ years. There was no difference in age between Black $(50.5 \pm 5.6)$ and White/Other $(51.2 \pm 6.0)$ participants. White/Other YBCS had higher education, were more likely to be employed, had higher income, and were less likely to be in "single" relationship status than Black YBCS (Table 1). Moreover, Black YBCS were less likely to have a routine source of care (chi-square $=5.84, p=0.016$ ), lacked access to care due to high out-of-pocket costs (chi-square $=22.95, p<$ 0.001 ), and lacked health insurance (chi-square $=7.73, p=$ 0.005). Black YBCS reported having Medicaid (chi-square = $67.14, p<0.001$ ), or Medicare (chi-square $=21.55, p<0.001$ ) health-care programs more frequently than White/Other YBCS. On the other hand, the latter were more likely to have private/other type of insurance (chi-square $=70.53$, $p<0.001)$.

The distance from the nearest board-certified counseling center was greater for White/Other (median $=10.3$ miles) than Black YBCS (median $=5.1$ miles), as indicated by the Wilcoxon rank sum test $(W=112,740, p<0.001)$. Cancer genetic counseling centers were operating predominantly in urban areas, where the population density of Black YBCS in the state of Michigan is high. At the time of the study there were 21 cancer genetic centers with board-certified/eligible genetic professionals in the state of Michigan. Of $n=353$ participating Black YBCS, approximately 1 of $3(n=100)$ lived in Detroit (located in southeast Michigan) at the time of the study. Of $n=473$ White/Other YBCS who resided in Michigan at the time of the study, the largest residential cluster was in Grand Rapids (western part of the state), and only a few White/Other YBCS lived in Detroit. We also identified more than 200 genetic services for participants living in other states at the time of the survey based on their ZIP codes.

Because clinical presentation of breast cancer, personal health history, and family health history influence referral to genetic services, we examined self-reported clinical characteristics between Black and White/Other YBCS. There was no difference in the years since diagnosis, or age at first diagnosis between Black and White/Other YBCS (Table 2). A larger proportion of White/Other were diagnosed with a DCIS compared with Black YBCS (chi-square $=11.66, p=0.001$ ). Invasive breast cancer and ovarian cancer were reported at similar rates. Reported family history of breast cancer was greater in White/Other compared with Black YBCS (chisquare $=4.80, p=0.028$ ). There was no difference in reported family history of other types of cancer including ovarian, or
Table 2 Clinical characteristics of young breast cancer survivors (YBCS)

\begin{tabular}{|c|c|c|c|c|}
\hline Characteristic & YBCS & $\begin{array}{l}\text { White/ } \\
\text { Other }\end{array}$ & Black & $\begin{array}{l}p \\
\text { value }\end{array}$ \\
\hline Years since diagnosis $^{a}$ & $\begin{array}{l}11.2 \pm \\
4.0\end{array}$ & $11.3 \pm 4.0$ & $\begin{array}{l}11.1 \pm \\
4.0\end{array}$ & 0.471 \\
\hline $\begin{array}{l}\text { Age at first cancer } \\
\text { diagnosis }^{a}\end{array}$ & $\begin{array}{l}40.1 \pm \\
4.7\end{array}$ & $40.1 \pm 4.7$ & $\begin{array}{l}39.6 \pm \\
4.8\end{array}$ & 0.094 \\
\hline \multicolumn{5}{|l|}{ Cancer diagnoses $^{\mathrm{b}}$} \\
\hline Invasive breast cancer & $\begin{array}{l}461 \\
(53.7)\end{array}$ & $279(53.8)$ & $\begin{array}{l}182 \\
(53.5)\end{array}$ & 0.948 \\
\hline $\begin{array}{l}\text { Ductal carcinoma in situ } \\
\text { (DCIS) }\end{array}$ & $\begin{array}{l}437 \\
(50.9)\end{array}$ & $303(58.4)$ & $\begin{array}{l}134 \\
(39.4)\end{array}$ & 0.001 \\
\hline Ovarian cancer & $8(0.9)$ & $5(1.0)$ & $3(0.9)$ & 0.904 \\
\hline \multicolumn{5}{|l|}{ Surgical treatment ${ }^{b}$} \\
\hline Lumpectomy & $\begin{array}{l}539 \\
(62.7)\end{array}$ & $324(62.4)$ & $\begin{array}{l}215 \\
(63.2)\end{array}$ & 0.811 \\
\hline Mastectomy & $\begin{array}{l}504 \\
(58.7)\end{array}$ & $315(60.7)$ & $\begin{array}{l}189 \\
(55.6)\end{array}$ & 0.137 \\
\hline Breast reconstruction & $\begin{array}{l}351 \\
(40.9)\end{array}$ & $238(45.9)$ & $\begin{array}{l}113 \\
(33.2)\end{array}$ & $<0.001$ \\
\hline Prophylactic mastectomy & $\begin{array}{l}124 \\
(14.4)\end{array}$ & $74(14.3)$ & $\begin{array}{l}50 \\
(14.7)\end{array}$ & 0.835 \\
\hline $\begin{array}{l}\text { Prophylactic } \\
\text { oophorectomy }\end{array}$ & $\begin{array}{l}141 \\
(16.4)\end{array}$ & $95(18.3)$ & $\begin{array}{l}46 \\
(13.5)\end{array}$ & 0.101 \\
\hline \multicolumn{5}{|l|}{ Family history of cancer ${ }^{b}$} \\
\hline Any cancer & $\begin{array}{l}713 \\
(83.0)\end{array}$ & $442(85.2)$ & $\begin{array}{l}271 \\
(79.7)\end{array}$ & 0.119 \\
\hline Breast & $\begin{array}{l}430 \\
(50.1)\end{array}$ & $276(53.2)$ & $\begin{array}{l}154 \\
(45.3)\end{array}$ & 0.024 \\
\hline Ovarian cancer & $\begin{array}{l}122 \\
(14.2)\end{array}$ & $65(12.5)$ & $\begin{array}{l}57 \\
(16.8)\end{array}$ & 0.082 \\
\hline Male breast cancer & $17(2.0)$ & $10(1.9)$ & $7(2.1)$ & 0.254 \\
\hline \multicolumn{5}{|l|}{ Genetic counseling/testing } \\
\hline Had genetic counseling & $\begin{array}{l}281 \\
(32.7)\end{array}$ & $192(37.0)$ & $\begin{array}{l}89 \\
(26.2)\end{array}$ & 0.001 \\
\hline Had genetic testing & $\begin{array}{l}230 \\
(26.8)\end{array}$ & $170(32.8)$ & $\begin{array}{l}60 \\
(17.6)\end{array}$ & $<0.001$ \\
\hline$B R C A 1$ or $B R C A 2$ positive & $36(4.2)$ & $28(5.4)$ & $8(2.4)$ & $0.045^{c}$ \\
\hline
\end{tabular}

All values expressed as $n(\%)$ with valid percentages shown to account for missing values.

${ }^{a}$ Mean \pm standard deviation.

b Values do not add up to $100 \%$ due to the possibility of multiple diagnoses.

${ }^{c}$ Chi-square test with Yates correction.

male breast cancers. As we presented in our previous publication, a greater proportion of White/Other reported having genetic counseling than Black YBCS, and more White/ Other reported having genetic testing than Blacks. ${ }^{20}$ Among 58 YBCS who reported having been identified as germline carriers of pathogenic variants, more White/Other reported a $B R C A 1$ or BRCA2 pathogenic variant than Black YBCS (chisquare $=4.01, p=0.045)$. There was no difference on reported rates of lumpectomy or mastectomy between Black 
Table 3 Multiple linear regression analyses to identify factors associated with knowledge of breast cancer (BC) risk factors and genetics

1. Knowledge of $B C$ risk factors

\begin{tabular}{|llll} 
& Estimate & SE & $p$ value \\
\hline Demographic characteristics & & & \\
\hline Race (Black vs. White/Other) & $-\mathbf{3 . 6 5}$ & $\mathbf{0 . 4 5}$ & $<\mathbf{0 . 0 0 1}$ \\
\hline Age & 0.01 & 0.05 & 0.990 \\
\hline Education & $\mathbf{1 . 3 4}$ & $\mathbf{0 . 2 0}$ & $<\mathbf{0 . 0 0 1}$ \\
\hline Income & -0.02 & 0.03 & 0.476 \\
\hline Clinical characteristics & & & \\
\hline Family history of breast/ovarian cancer & $\mathbf{0 . 4 5}$ & $\mathbf{0 . 1 9}$ & $\mathbf{0 . 0 1 9}$ \\
\hline Years since diagnosis & -0.04 & 0.07 & 0.592 \\
\hline Genetic counseling & $\mathbf{1 . 3 1}$ & $\mathbf{0 . 4 8}$ & $\mathbf{0 . 0 0 6}$ \\
\hline Access to health services & & & \\
\hline No insurance & -1.05 & 0.96 & 0.274 \\
\hline No routine source of care & 1.22 & 0.88 & 0.166 \\
\hline High out-of-pocket costs & 0.03 & 0.63 & 0.959 \\
\hline Distance from genetic counseling centers & 0.01 & 0.01 & 0.352 \\
\hline 2. Knowledge of BC genetics & & & \\
\hline & $\mathbf{E s t i m a t e}$ & $\mathbf{S E}$ & $\mathbf{p}$ value \\
\hline Demographic characteristics & & & \\
\hline Race (Black vs. White/Other) & $-\mathbf{1 . 4 9}$ & $\mathbf{0 . 2 8}$ & $<\mathbf{0 . 0 0 1}$ \\
\hline Age & -0.01 & 0.03 & 0.868 \\
\hline Education & $\mathbf{0 . 7 1}$ & $\mathbf{0 . 1 2}$ & $<\mathbf{0 . 0 0 1}$ \\
\hline Income & -0.03 & 0.02 & 0.111 \\
\hline Clinical characteristics & & & \\
\hline Family history of breast/ovarian cancer & $\mathbf{0 . 0 2}$ & $\mathbf{0 . 1 2}$ & $\mathbf{0 . 8 9 1}$ \\
\hline Years since diagnosis & 0.02 & 0.04 & 0.701 \\
\hline Genetic counseling & $\mathbf{1 . 7 2}$ & $\mathbf{0 . 2 9}$ & $<\mathbf{0 . 0 0 1}$ \\
\hline Access to health services & & & \\
\hline No insurance & -0.62 & 0.59 & 0.295 \\
\hline No routine source of care & 0.41 & 0.54 & 0.445 \\
\hline High out-of-pocket costs & -0.10 & 0.39 & 0.802 \\
\hline Distance from genetic counseling centers & -0.01 & 0.01 & 0.779 \\
\hline & & & \\
\hline
\end{tabular}

and White/Other YBCS, yet, a greater proportion of White/ Other had breast reconstruction (chi-square $=13.54, p<$ 0.001).

Attitudes toward breast cancer risk, perceived risk, and fear of cancer recurrence did not differ between Black and White/ Other YBCS. Knowledge of breast cancer risk factors was significantly lower among Black YBCS $(4.1 \pm 6.8)$ compared with White/Other $(8.4 \pm 5.9)$, as verified by the Wilcoxon rank sum test $(W=121,350, p<0.001)$. Knowledge of breast cancer genetics was also lower in Black YBCS $(3.8 \pm 4.1)$ compared with White/Other $(5.8 \pm 3.8 ; W=113,110, p<$ 0.001). A multivariate linear regression model examined potential factors associated with these knowledge scores (Table 3). The results of the regression indicated that 11 predictors explained $17.4 \%$ of the variance $\left(R^{2}=0.174, F\right.$ $(11,794)=16.45, p<0.001)$, regarding knowledge of breast cancer risk factors, and $14 \%\left(R^{2}=0.14, F(11,798)=13.01, p\right.$ $<0.001)$ regarding knowledge of breast cancer genetics. Black race was associated with less knowledge of both breast cancer risk factors $(B=-3.65, p<0.001)$ and breast cancer genetics $(B=-1.49, p<0.001)$. YBCS with more family members affected by breast/ovarian cancer were more likely to have higher knowledge of risk factors $(B=0.45, p=0.019)$. Higher education $(B=1.34, p<0.001)$ and having genetic counseling $(\mathrm{B}=1.31, \mathrm{p}=0.006)$ were positive predictors of higher knowledge of breast cancer risk factors. They were also positive predictors of higher knowledge of breast cancer genetics $(B=0.71, \quad p<0.001$, and $B=1.72, \quad p<0.001$, respectively).

Having genetic counseling and having genetic testing were highly correlated among YBCS $(r=0.79, p<0.001)$. That was true for both Black YBCS $(r=0.69, p<0.001)$ and White/ Other $(r=0.88, p<0.001)$. However, a greater proportion of White/Other YBCS who reported having genetic counseling also reported having genetic testing $(n=170 / 192 ; 88.5 \%)$, compared with Black YBCS $(n=60 / 84,71.4 \%$; chi-square $=$ 12.32, $p<0.001)$. Logistic regressions assessed potential reasons that explain use of genetic services among YBCS (Table 4). Black race (odds ratio $[\mathrm{OR}]=0.62$, confidence interval $[\mathrm{CI}] 95 \%=0.44-0.89)$, high out-of-pocket costs (OR $=0.51$, CI $95 \%=0.30-0.88)$, older age $(\mathrm{OR}=0.96$, CI $95 \%=$ $0.44-0.99)$, and years since diagnosis ( OR $=0.92$, CI $95 \%=$ 0.87-0.97) were negative predictors of genetic counseling uptake. On the other hand, higher education $(\mathrm{OR}=1.23, \mathrm{CI}$ $95 \%=1.05-1.45)$, family history of breast/ovarian cancer $(\mathrm{OR}=1.52$, CI $95 \%=1.31-1.76)$, and fear of cancer recurrence $(\mathrm{OR}=1.16, \mathrm{CI} 95 \%=1.04-1.28)$ were positively associated with genetic counseling. The same predictors were identified for genetic testing uptake.

The baseline survey also collected data for YBCS who did not use genetic services. In our previous publication, we reported reasons that Black YBCS did not use genetic services. $^{20}$ Here we provide reasons for not using genetic services for the entire sample (Table 5). Potential answers included an extended list of options, such as provider-related factors (e.g., no one ever suggested it), availability of services (e.g., out-of-pocket expenses too high/not covered by insurance), accessibly of services (e.g., clinics are too far away), and acceptability of services (e.g., too scared/would rather not know). The most frequent reason for not using genetic services among all YBCS was lack of physician recommendation $(n=375,43.7 \%)$. Moreover, a higher proportion of Black YBCS reported no physician recommendation $(n=172,50.6 \%)$ compared with White/Other $(n=$ 203, 39.1\%; chi-square $=10.97, p<0.001$ ).

\section{DISCUSSION}

Racial disparities in genetic services utilization are an important problem of health equity in the United States. In this study, only $26.2 \%$ of Black YBCS reported receiving genetic counseling, and $17.6 \%$ reported genetic testing, as opposed to $37 \%$ and $32.8 \%$ of White/Other YBCS, respectively. These figures are in agreement with what has been reported in the literature. ${ }^{13,15,28,29}$ Findings from this study 
Table 4 Logistic regression analyses to identify factors associated with genetic services (counseling and testing) utilization among YBCS

1. Genetic counseling

$(N=281)$

$$
\text { Estimate } \mathrm{SE} \quad \mathrm{OR} \quad \mathrm{Cl} 95 \% \quad p
$$
value

\begin{tabular}{|c|c|c|c|c|c|}
\hline \multicolumn{6}{|l|}{ Demographic characteristics } \\
\hline $\begin{array}{l}\text { Race (Black vs. White/ } \\
\text { Other) }\end{array}$ & -0.47 & 0.18 & 0.62 & $0.44-0.89$ & 0.010 \\
\hline Age & -0.04 & 0.02 & 0.96 & $0.93-0.99$ & 0.033 \\
\hline Education & 0.21 & 0.08 & 1.23 & $1.05-1.45$ & 0.012 \\
\hline Income & 0.01 & 0.01 & 1.00 & $0.98-1.03$ & 0.774 \\
\hline \multicolumn{6}{|l|}{ Clinical characteristics } \\
\hline $\begin{array}{l}\text { Family history of breast/ } \\
\text { ovarian cancer }\end{array}$ & 0.42 & 0.07 & 1.52 & $1.31-1.76$ & $<0.001$ \\
\hline Years since diagnosis & -0.09 & 0.03 & 0.92 & $0.87-0.97$ & 0.002 \\
\hline \multicolumn{6}{|l|}{ Access to health services } \\
\hline No insurance & -0.63 & 0.47 & 0.53 & $0.21-1.35$ & 0.184 \\
\hline $\begin{array}{l}\text { No routine source of } \\
\text { care }\end{array}$ & -0.23 & 0.40 & 1.25 & $0.58-2.72$ & 0.568 \\
\hline High out-of-pocket costs & -0.67 & 0.28 & 0.51 & $0.30-0.88$ & 0.015 \\
\hline $\begin{array}{l}\text { Distance from genetic } \\
\text { counseling centers }\end{array}$ & -0.01 & 0.01 & 1.00 & $0.99-1.00$ & 0.184 \\
\hline \multicolumn{6}{|l|}{ Attitudes } \\
\hline Perceived risk & -0.07 & 0.04 & 0.94 & $0.87-1.00$ & 0.064 \\
\hline $\begin{array}{l}\text { Fear of cancer } \\
\text { recurrence }\end{array}$ & 0.14 & 0.05 & 1.16 & $1.04-1.28$ & 0.005 \\
\hline
\end{tabular}

2. Genetic testing $(\boldsymbol{N}=230)$

Estimate SE OR $\quad \mathrm{Cl} 95 \% \quad p$ value

\section{Demographic characteristics}

Race (Black vs. White/ $\quad-0.89 \quad 0.21 \quad 0.41 \quad 0.27-0.63 \quad<0.001$

Other)

\begin{tabular}{|c|c|c|c|c|c|}
\hline Age & -0.06 & 0.02 & 0.94 & $0.90-0.98$ & 0.002 \\
\hline Education & 0.30 & 0.09 & 1.35 & $1.12-1.62$ & 0.001 \\
\hline Income & 0.01 & 0.02 & 1.01 & $0.98-1.04$ & 0.441 \\
\hline \multicolumn{6}{|l|}{ Clinical characteristics } \\
\hline $\begin{array}{l}\text { Family history of breast/ } \\
\text { ovarian cancer }\end{array}$ & 0.48 & 0.08 & 1.62 & $1.38-1.90$ & $<0.001$ \\
\hline Years since diagnosis & -0.10 & 0.02 & 0.90 & $0.85-0.96$ & 0.001 \\
\hline \multicolumn{6}{|l|}{ Access to health services } \\
\hline No insurance & -0.47 & 0.52 & 0.63 & $0.23-1.72$ & 0.365 \\
\hline $\begin{array}{l}\text { No routine source of } \\
\text { care }\end{array}$ & -0.19 & 0.44 & 1.21 & $0.51-2.84$ & 0.667 \\
\hline High out-of-pocket costs & -0.64 & 0.31 & 0.53 & $0.29-0.97$ & 0.039 \\
\hline $\begin{array}{l}\text { Distance from genetic } \\
\text { counseling centers }\end{array}$ & -0.01 & 0.01 & 1.00 & $0.99-1.00$ & 0.205 \\
\hline \multicolumn{6}{|l|}{ Attitudes } \\
\hline Perceived risk & -0.07 & 0.04 & 0.93 & $0.86-1.01$ & 0.097 \\
\hline Fear of cancer & 0.19 & 0.06 & 1.21 & $1.07-1.35$ & 0.001 \\
\hline
\end{tabular}

Cl confidence interval, OR odds ratio, YBCS young breast cancer survivors.
Table 5 Reasons for not seeking cancer genetic services

\begin{tabular}{|c|c|c|c|}
\hline Reason & YBCS & $\begin{array}{l}\text { White/ } \\
\text { Other }\end{array}$ & Black \\
\hline \multicolumn{4}{|l|}{ Provider-related factors } \\
\hline No one ever suggested & $\begin{array}{l}375 \\
(43.7)\end{array}$ & $\begin{array}{l}203 \\
(39.1)\end{array}$ & $\begin{array}{l}172 \\
(50.6)\end{array}$ \\
\hline Provider said was not necessary & $6(0.7)$ & $3(0.6)$ & $3(0.9)$ \\
\hline $\begin{array}{l}\text { Don't know where to go for cancer } \\
\text { genetic services }\end{array}$ & $1(0.1)$ & $1(0.2)$ & $0(0)$ \\
\hline $\begin{array}{l}\text { Did not know cancer genetic services } \\
\text { existed }\end{array}$ & $6(0.7)$ & $3(0.6)$ & $3(0.9)$ \\
\hline \multicolumn{4}{|l|}{ Availability of services } \\
\hline $\begin{array}{l}\text { Out-of-pocket expenses are too high/not } \\
\text { covered by insurance }\end{array}$ & $\begin{array}{l}72 \\
(8.4)\end{array}$ & $\begin{array}{l}57 \\
(11.0)\end{array}$ & $\begin{array}{l}15 \\
(4.4)\end{array}$ \\
\hline Lack of transportation & $9(1.0)$ & $1(0.2)$ & $8(2.4)$ \\
\hline \multicolumn{4}{|l|}{ Accessibility of services } \\
\hline I am too busy & $4(0.5)$ & $2(0.4)$ & $2(0.6)$ \\
\hline I cannot get time off work & $7(0.8)$ & $4(0.8)$ & $3(0.9)$ \\
\hline $\begin{array}{l}\text { My disability makes it difficult to carry out } \\
\text { daily activities }\end{array}$ & $\begin{array}{l}11 \\
(1.3)\end{array}$ & $3(0.6)$ & $8(2.4)$ \\
\hline Clinic hours do not fit my schedule & $3(0.3)$ & $1(0.2)$ & $2(0.6)$ \\
\hline Clinics are too far away & $6(0.7)$ & $4(0.8)$ & $2(0.6)$ \\
\hline \multicolumn{4}{|l|}{ Acceptability of services } \\
\hline Other life issues come up more important & $\begin{array}{l}13 \\
(1.5)\end{array}$ & $9(1.7)$ & $4(1.2)$ \\
\hline I am too sick from cancer treatment & $3(0.3)$ & $1(0.2)$ & $2(0.6)$ \\
\hline $\begin{array}{l}\text { I am the only person with cancer in my } \\
\text { family }\end{array}$ & $\begin{array}{l}10 \\
(1.2)\end{array}$ & $7(1.3)$ & $3(0.9)$ \\
\hline Relative tested negative & $2(0.2)$ & $1(0.2)$ & $1(0.3)$ \\
\hline Not interested & $4(0.5)$ & $3(0.6)$ & $1(0.3)$ \\
\hline Unknown benefit & $\begin{array}{l}16 \\
(1.9)\end{array}$ & $13(2.5)$ & $3(0.9)$ \\
\hline I am afraid it will be used against me & $7(0.8)$ & $7(1.3)$ & $0(0)$ \\
\hline Scared/would rather not know & $\begin{array}{l}10 \\
(1.2)\end{array}$ & $6(1.2)$ & $4(1.2)$ \\
\hline
\end{tabular}

Multiple-choice responses for not using cancer genetic services. All values expressed as $n(\%)$ with valid percentages.

$Y B C S$ young breast cancer survivors.

suggest that out-of-pocket costs are negatively associated with use of genetic services. Others reported that low-income women are less apt to receive genetic testing, even after controlling for race, ethnicity, and other sociodemographic factors. ${ }^{30}$ Taken together, these findings indicate that even modest cost-sharing requirements can prove burdensome for some YBCS. Additional expenses that usually follow a genetic diagnosis can be prohibitive, and out-of-pocket spending for surveillance needs, chemotherapy, and risk-reducing surgery can act as an additional barrier for accessing genetic services. $^{28,31}$

Racial segregation and poverty have been proposed as the main reasons for health disparities. ${ }^{15,18}$ One of the main factors that deprives minority communities of quality care is distance to health-care services. ${ }^{16}$ However, in our study the median distance from the nearest board-certified genetic 
counseling center was almost half for Black YBCS compared with White/Other YBCS. Cancer genetic clinics usually segregate in large urban areas and tertiary care centers. Approximately one in three participating Black YBCS, who resided in Michigan at the time of the study, lived in Detroit, the largest urban area in the state, and which has the greatest number of cancer genetic clinics. Hence, lack of proximity to genetic services does not suffice to explain these differences in genetic services utilization. We must investigate other accessibility and/or acceptability issues, including lack of safe and reliable public transportation. It is nationally recognized that most genetic testing is not performed through genetic counselors, but rather outside the genetic counseling setting. We are not certain if this finding can be explained because the state of Michigan is different from other states, or because this is among the first studies to use geocoding to investigate how proximity to cancer genetic services impacts utilization of such services. Thus, this finding warrants further examination.

Our findings suggest that YBCS who were older, less educated, did not have a family history of breast and/or ovarian cancer, or were not aware of their family history were less likely to receive genetic counseling and testing. Several studies have shown that use of genetic services is associated with awareness of familial risk. ${ }^{20,28,32}$ Black YBCS in our sample reported lower rates of family history of breast/ovarian cancer compared with White/Other, suggesting that Black women may tend to underreport, or fail to recognize family history of cancer. ${ }^{15,33,34}$ Black YBCS in our sample also had lower knowledge of breast cancer risk factors and breast cancer genetics compared to White/Other. The most important predictor for this finding was educational level. As expected, genetic counseling increased knowledge of breast cancer risk factors and genetics, suggesting that genetic counseling is an important first step to using cancer genetic services.

Participants were also asked to report reasons for not using genetic services. Lack of physician recommendation was the single most common response, and this was reported more frequently by Black than White/Other YBCS. This finding has also been reported in other studies. ${ }^{14,15,29,35}$ Some studies have shown that minority-serving physicians were more reluctant to order genetic testing for Black women, because they were more concerned about cost and insurance coverage for these patients. ${ }^{36,37}$ Our findings are in agreement with others who have previously reported that minority-serving physicians were significantly less likely to have ever ordered a genetic test for breast cancer, colorectal cancer, or Huntington disease, or to have ever referred a patient for genetic testing compared with those serving fewer minorities. ${ }^{37}$ Our findings also suggest that low income and low educational attainment are complex barriers to receiving genetic services both at the individual (e.g., lack of knowledge) and at the health-care system (e.g., lack of provider recommendation) levels. ${ }^{15,18}$ Our study demonstrated this with a population-based sample that included a large number of Black YBCS, which addresses the knowledge gap identified by USPSTF about understanding disparities in genetic service utilization among racial and ethnic minorities. ${ }^{19}$ Other studies have reached similar conclusions. ${ }^{14,15,29,35}$ Longitudinal follow-up is critical to determine whether these disparities persist, or widen with time.

The study has several limitations, such as self-reported data, a cross-sectional design, and residential patterns, which may not be representative of other states besides the state of Michigan. Results of positive genetic tests (i.e., BRCA1 or $B R C A 2$ pathogenic variants) were based on self-reports and were not verified with data from medical files. A smaller proportion on Black YBCS accepted participation compared with White/Others. Given the lack of detailed demographic and clinical data for nonparticipating YBCS, it was not possible to assess how this may have affected the outcome of the study. There is a possibility for selection bias among responders. Moreover, participants who were not identified as Black were collapsed into the same category as Whites. This could have potentially decreased the observed difference in racial disparities, especially if these participants shared the same barriers as Black YBCS. However, a sensitivity analysis was conducted, and showed that this did not affect the reported outcomes.

Despite these limitations, this study has many strengths. Our study was one of the few that examined the impact of distance from genetic counseling services as a barrier, using geocoding of genetic counseling centers across the country, and residential ZIP codes of all participants (approximately 12\% of participants lived in 23 other US states, besides Michigan). Our findings indicate that distance to genetic services does not explain observed racial disparities when using these services, and that increasing availability of genetic services may not be adequate to close this gap. Few registry-based studies have achieved significant representation of Black YBCS. ${ }^{15,29}$ Having a larger sample of Black YBCS enabled racial comparisons to be conducted with enough statistical power. Furthermore, this study can serve as a reference for future comparisons. This may be particularly important for assessing the impact of the Affordable Care Act (ACA) on genetic services utilization. ${ }^{38}$ The Healthy Michigan Plan (Medicaid expansion) was put in action in April 2014, and has granted access to genetic testing and cancer preventive measures (e.g., mammographic surveillance, chemotherapy, and/or prophylactic surgery) to more than 650,000 previously uninsured individuals, most of whom belong to minority groups. ${ }^{29,38}$ Thus, our study can serve as a standard for comparing genetic service utilization (pre- and post-ACA implementation) in a model state, and provide evidence on its broader social and economic impact. ${ }^{39}$ This is particularly important following discussions concerning ACA continuation, or proposed dismissal after the fiscal year 2020.

Additional initiatives that include interventions tailored to the unique needs and special characteristics of racial groups need to be considered. The primary focus of system-based interventions should be on mitigating social and health-care inequalities created by disparities in income and education. 
Once the financial barriers have been bridged, more attention should be given to empowering minority communities by strengthening their knowledge of genetic cancer risk, and increasing appropriate use of genetic services. ${ }^{40}$

\section{ACKNOWLEDGEMENTS}

This study was supported by the Centers for Disease Control and Prevention (CDC), 5U48DP001901-03, and by the Robert Wood Johnson Foundation (RWJF)—Nurse Faculty Scholars 68039 Award to M.C.K. We thank Jenna McLosky, Michigan Department of Health and Human Services, for YBCS recruitment.

\section{DISCLOSURE}

The authors declare no conflicts of interest.

\section{REFERENCES}

1. American Cancer Society. Breast cancer facts and figures. 2017. https:// cancerstatisticscenter.cancer.org. Accessed 29 October 2018.

2. O'Keefe EB, Meltzer JP, Bethea TN. Health disparities and cancer: racial disparities in cancer mortality in the United States, 2000-2010. Front Public Health. 2015;3:51.

3. Danforth DN Jr. Disparities in breast cancer outcomes between Caucasian and African American women: a model for describing the relationship of biological and nonbiological factors. Breast Cancer Res. 2013;15:208.

4. Dietze EC, Sistrunk C, Miranda-Carboni G, O'Regan R, Seewaldt VL. Triple-negative breast cancer in African-American women: disparities versus biology. Nat Rev Cancer. 2015;15:248-254.

5. Meredith SM. Disparities in breast cancer and the role of patient navigator programs. Clin J Oncol Nurs. 2013;17:54-59.

6. Anderson B, McLosky J, Wasilevich E, Lyon-Callo S, Duquette D, Copeland G. Barriers and facilitators for utilization of genetic counseling and risk assessment services in young female breast cancer survivors. J Cancer Epidemiol. 2012;2012:298745.

7. Rosenberg SM, Newman LA, Partridge AH. Breast cancer in young women: rare disease or public health problem? JAMA Oncol. 2015, 1:877-878.

8. Schwartz MD, Isaacs C, Graves KD, et al. Long-term outcomes of BRCA1/ BRCA2 testing: risk reduction and surveillance. Cancer. 2012;118: 510-517.

9. Garcia C, Wendt J, Lyon L, et al. Risk management options elected by women after testing positive for a BRCA mutation. Gynecol Oncol. 2014;132:428-433.

10. Mai PL, Vadaparampil ST, Breen N, McNeel TS, Wideroff L, Graubard BI. Awareness of cancer susceptibility genetic testing: the 2000, 2005, and 2010 National Health Interview Surveys. Am J Prev Med. 2014;46: 440-448.

11. Kolb B, Wallace AM, Hill D, Royce M. Disparities in cancer care among racial and ethnic minorities. Oncology (Williston Park). 2006;20: 1256-1261.

12. Pal T, Vadaparampil ST. Genetic risk assessments in individuals at high risk for inherited breast cancer in the breast oncology care setting. Cancer Control. 2012;19:255-266.

13. Armstrong K, Micco E, Carney A, Stopfer J, Putt M. Racial differences in the use of BRCA1/2 testing among women with a family history of breast or ovarian cancer. JAMA. 2005;293:1729-1736.

14. Jagsi $R$, Griffith KA, Kurian AW, et al. Concerns about cancer risk and experiences with genetic testing in a diverse population of patients with breast cancer. J Clin Oncol. 2015;33:1584-1591.

15. McCarthy AM, Bristol M, Domchek SM, et al. Health care segregation, physician recommendation, and racial disparities in BRCA1/2 testing among women with breast cancer. J Clin Oncol. 2016;34:2610-2618.

16. Dai DJ. Black residential segregation, disparities in spatial access to health care facilities, and late-stage breast cancer diagnosis in metropolitan Detroit. Health Place. 2010;16:1038-1052.

17. Haas JS, Earle CC, Orav JE, et al. Racial segregation and disparities in breast cancer care and mortality. Cancer. 2008;113:2166-2172.

18. Russell EF, Kramer MR, Cooper HLF, Gabram-Mendola S, Senior-Crosby D, Arriola KRJ. Metropolitan area racial residential segregation, neighborhood racial composition, and breast cancer mortality. Cancer Causes Control. 2012;23:1519-1527

19. Moyer VA, U.S. Preventive Services Task Force. Risk assessment, genetic counseling, and genetic testing for BRCA-related cancer in women: U.S. Preventive Services Task Force recommendation statement. Ann Intern Med. 2014;160:271-281.

20. Jones T, Lockhart JS, Mendelsohn-Victor KE, et al. Use of cancer genetics services in African-American young breast cancer survivors. Am J Prev Med. 2016;51:427-436.

21. Katapodi MC, Northouse LL, Schafenacker AM, et al. Using a state cancer registry to recruit young breast cancer survivors and high-risk relatives: protocol of a randomized trial testing the efficacy of a targeted versus a tailored intervention to increase breast cancer screening. BMC Cancer. 2013;13:97.

22. Katapodi MC, Duquette D, Yang JJ, et al. Recruiting families at risk for hereditary breast and ovarian cancer from a statewide cancer registry: a methodological study. Cancer Causes Control. 2017; 28:191-201.

23. Katapodi $M C$, Aouizerat $B E$. Do women in the community recognize hereditary and sporadic breast cancer risk factors? Oncol Nurs Forum. 2005:32:617-623.

24. Katapodi MC, Dodd MJ, Lee KA, Facione NC. Underestimation of breast cancer risk: influence on screening behavior. Oncol Nurs Forum. 2009;36:306-314

25. Vickberg SM. The Concerns About Recurrence Scale (CARS): a systematic measure of women's fears about the possibility of breast cancer recurrence. Ann Behav Med. 2003;25:16-24.

26. Bliss RL, Katz JN, Wright EA, Losina E. Estimating proximity to care: are straight line and zipcode centroid distances acceptable proxy measures? Med Care. 2012;50:99-106.

27. Faul F, Erdfelder E, Lang AG, Buchner A. G*Power 3: a flexible statistical power analysis program for the social, behavioral, and biomedical sciences. Behav Res Methods. 2007;39:175-191.

28. Levy DE, Byfield SD, Comstock CB, et al. Underutilization of BRCA1/2 testing to guide breast cancer treatment: black and Hispanic women particularly at risk. Genet Med. 2011;13:349-355.

29. Cragun D, Weidner A, Lewis $C$, et al. Racial disparities in BRCA testing and cancer risk management across a population-based sample of young breast cancer survivors. Cancer. 2017;123:2497-2505.

30. Levy DE, Garber JE, Shields AE. Guidelines for genetic risk assessment of hereditary breast and ovarian cancer: early disagreements and low utilization. J Gen Intern Med. 2009;24:822-828.

31. Thompson HS, Valdimarsdottir HB, Jandorf L, Redd W. Perceived disadvantages and concerns about abuses of genetic testing for cancer risk: differences across African American, Latina and Caucasian women. Patient Educ Couns. 2003;51:217-227.

32. Cragun D, Bonner D, Kim J, et al. Factors associated with genetic counseling and BRCA testing in a population-based sample of young Black women with breast cancer. Breast Cancer Res Treat. 2015;151:169-176.

33. Murff HJ, Byrne D, Haas JS, Puopolo AL, Brennan TA. Race and family history assessment for breast cancer. J Gen Intern Med. 2005; 20:75-80.

34. Hurle B, Citrin T, Jenkins JF, et al. What does it mean to be genomically literate?: National Human Genome Research Institute meeting report. Genet Med. 2013;15:658-663.

35. Kurian AW, Griffith KA, Hamilton AS, et al. Genetic testing and counseling among patients with newly diagnosed breast cancer. JAMA. 2017:317:531-534.

36. Shields $A E$, Burke W, Levy DE. Differential use of available genetic tests among primary care physicians in the United States: results of a national survey. Genet Med. 2008;10:404-414.

37. Graves KD, Christopher J, Harrison TM, Peshkin BN, Isaacs C, Sheppard VB. Providers' perceptions and practices regarding BRCA1/2 genetic counseling and testing in African American women. J Genet Couns. 2011;20:674-689.

38. Ayanian JZ, Ehrlich GM, Grimes DR, Levy H. Economic effects of Medicaid expansion in Michigan. N Engl J Med. 2017;376:407-410.

39. Sabik LM, Adunlin G. The ACA and cancer screening and diagnosis. Cancer J. 2017;23:151-162.

40. Bonham VL, Citrin T, Modell SM, Franklin TH, Bleicher EW, Fleck LM. Community-based dialogue: engaging communities of color in the United States' genetics policy conversation. J Health Polit Policy Law. 2009;34:325-359. 